Hydrol. Earth Syst. Sci., 17, 2717-2733, 2013

www.hydrol-earth-syst-sci.net/17/2717/2013/

doi:10.5194/hess-17-2717-2013

(C) Author(s) 2013. CC Attribution 3.0 License.

\title{
The influence of decadal-scale variability on trends in long European streamflow records
}

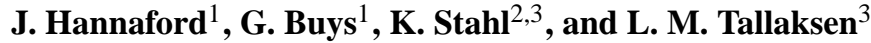 \\ ${ }^{1}$ Centre for Ecology and Hydrology, Wallingford, UK \\ ${ }^{2}$ Institute of Hydrology, University of Freiburg, Germany \\ ${ }^{3}$ Department of Geosciences, University of Oslo, Norway
}

Correspondence to: J. Hannaford (jaha@ceh.ac.uk)

Received: 17 January 2013 - Published in Hydrol. Earth Syst. Sci. Discuss.: 8 February 2013

Revised: 15 May 2013 - Accepted: 28 May 2013 - Published: 15 July 2013

\begin{abstract}
This study seeks to provide a long-term context for the growing number of trend analyses which have been applied to river flows in Europe. Most studies apply trend tests to fixed periods, in relatively short (generally 1960s-present) records. This study adopts an alternative "multi-temporal" approach, whereby trends are fitted to every possible combination of start and end years in a record. The method is applied to 132 catchments with long (1932-2004) hydrometric records from northern and central Europe, which were chosen as they are minimally anthropogenically influenced and have good quality data. The catchments are first clustered into five regions, which are broadly homogenous in terms of interdecadal variability of annual mean flow. The multitemporal trend approach was then applied to regional time series of different hydrological indicators (annual, monthly and high and low flows). The results reveal that the magnitude and even direction of short-term trends are heavily influenced by interdecadal variability. Some short-term trends revealed in previous studies are shown to be unrepresentative of long-term change. For example, previous studies have identified post-1960 river flow decreases in southern and eastern Europe: in parts of eastern Europe, these trends are resilient to study period, extending back to the 1930s; in southern France, longer records show evidence of positive trends which reverse from the 1960s. Recent (post-1960) positive trends in northern Europe are also not present in longer records, due to decadal variations influenced by the North Atlantic Oscillation. The results provide a long-term reference for comparison with published and future studies. The multi-temporal approach advocated here is recommended for use in future trend assessments, to help contex-
\end{abstract}

tualise short-term trends. Future work should also attempt to explain the decadal-scale variations that drive short-term trends, and thus develop more sophisticated methods for trend detection that take account of interdecadal variability and its drivers.

\section{Introduction}

Globally, there is growing concern that anthropogenic climate change is intensifying the hydrological cycle (Huntington, 2006), which is causing changes to streamflow regimes and leading to more frequent and severe floods and droughts. There is a growing need, therefore, for observational data with which to discern any emerging trends in river flows, and to compare these with future projections from climate models.

The need to detect and attribute the influence of climate change on streamflows has led to considerable scientific effort being focused on trend testing using observed hydrometric data. The last decade has seen a proliferation of studies of streamflow trends using a diversity of flow indicators (of magnitude, frequency and extremes) in a wide variety of environmental settings. There has been an abundance of national studies, with an increasing number focusing exclusively on trends in specialised networks of near-natural catchments gauged by stations providing good quality data. The motivation for this approach is to ensure that trends can be related to climate variability rather than direct anthropogenic influences (such as dam construction or changes in abstractions) or inhomogeneities relating to data quality. For 
recent reviews of the importance of such "reference" hydrometric networks (RHNs), see Whitfield et al. (2012), who discuss the current status of such networks globally, and Burn et al. (2012), who review the application of RHNs for climate detection. Examples of countries with national RHN studies include Canada (Burn et al., 2010), UK (Hannaford and Marsh, 2008; Hannaford and Buys, 2012), France (Renard et al., 2008; Giuntoli et al., 2013), and Ireland (Murphy et al., 2013).

Some studies have compared streamflow trends between countries and across larger scales, but most regional- and global-scale studies have focused on large, non-reference basins which are anthropogenically disturbed, e.g. Milly et al. (2005), Svensson et al. (2005), Dai et al. (2009), Shiklomanov and Lammers (2009). A more defensible approach, for climate attribution purposes, is to integrate data from RHNs. Several recent studies compared trends between RHNs, or have applied reference network criteria to create international RHN-like networks. Hodgkins and Dudley (2006) compared trends from RHNs in the USA and Canada. Wilson et al. (2010) examined trends from an RHNlike network across the Nordic countries. At a larger scale still, Rennermalm et al. (2010) assembled data from RHNlike catchments across the entire Arctic region, and carried out a trend analysis on low streamflow regimes. At the panEuropean scale, Stahl et al. (2010) assembled a dataset of near-natural catchments, and examined trends in mean flow, monthly flow and low flows. An additional benefit of these studies is that detailed spatial patterns of the regional response to any climate signal can be discerned by using a high number of small reference catchments.

One of the inherent problems with observational data is that a majority of river flow records, globally, tend to be relatively short - the number of daily records on the Global Runoff Data Centre (GRDC, http://grdc.bafg.de/) starting in 1970 exceeds 3000, but this decreases markedly for longer periods, with $<600$ starting pre-1920 (Hannah et al., 2011). Kundzewicz and Robson (2004) recommend at least $50 \mathrm{yr}$ of record for hydro-climatic trend detection, but even in Europe the majority of records are shorter than this, starting from the 1960s or later. Furthermore, longer records (such as many held on the GRDC) are often from large catchments and subject to major anthropogenic disturbances.

In trend analyses, study periods are usually selected to represent a trade-off between record length and network density (Burn et al., 2012). For example, Stahl et al. (2010) used periods from 1962-2004 (441 stations), 1952-2004 (277 stations), 1942-2004 (171 stations) and 1932-2004 (132 stations). In common with most studies, the recent period provides the greatest geographical representativeness and is therefore afforded the most attention. As a result, and given that the majority of streamflow gauges in Europe start in the 1960s, the literature abounds with examples of significant trends from the 1960s to the first decade of the 2000s, whereas the evidence for trends from longer timescales generally receives far less attention.

An important consideration in interpreting the results of these studies is that a trend in any fixed period (even over a very long timescale) may be not be representative of historical variability. In particular, previous authors have noted that trends in short records may be heavily influenced by multi-decadal variability. Chen and Grasby (2009) used a simulation approach to caution that oscillations in hydro-climatic series can manifest themselves as trends on shorter timescales, and found evidence of such oscillations in long hydro-climatic records from Canada. Probst and Tardy (1987) found quasi-cyclical patterns in a number of long records on a global scale. In a similar, more recent global analysis, Pekarova et al. (2003) warn that trend tests should be carried out using periods that encompass one whole cycle from peak to peak or trough to trough (a cycle of $28 \mathrm{yr}$ for central Europe, for example between 19541981). The causative mechanisms behind such oscillations in streamflow are not immediately apparent and often not sought - or only hinted at - in such analyses. Nevertheless, a number of studies have shown that streamflow tends to exhibit long-term persistence (LTP) (e.g. Koutsoyiannis, 2003; Khaliq et al., 2009), which may be a function of the natural system that is simply not known or understood; even in the absence of understanding the causative process, LTP and cyclical behaviour can call into question the assumptions and interpretation of statistical trend tests (e.g. Cohn and Lins, 2005; Khaliq et al., 2009).

Whilst physical interpretation of LTP or quasi-cyclical patterns may prove elusive, it is clear that trends can be influenced by decadal-scale variations driven by physically based processes which are well understood, especially patterns of large-scale atmospheric circulation. For example, a wealth of studies have examined links between the North Atlantic Oscillation (NAO) and European streamflows (e.g. Hannaford and Marsh, 2008; Bouwer et al., 2008; Wrzesinski and Paluszkiewicz, 2010); in North America the Pacific Decadal Oscillation (PDO) has been linked to changes in streamflow regimes (Woo et al., 2006; Hodgkins, 2009); and in Australia variability in El-Niño/Southern Oscillation (ENSO) has been linked to persistent drought conditions (Ummenhofer et al., 2009). Apparent short-term trends can therefore be part of longer-term fluctuations driven by largescale atmospheric circulation. This can hamper the interpretation of trends and, in particular, hinders the attribution of trends to anthropogenic climate change as natural variability could obscure any underlying anthropogenic signal. Moreover, large-scale patterns of climatic variability such as the NAO are themselves influenced by anthropogenic forcing (e.g. Dong et al., 2011).

Largely as a result of the sensitivity of linear, monotonic trends to such quasi-cyclical oscillations or other patterns, some authors have advocated the use of "multi-temporal" trend analyses, which generally involve applying standard 
trend tests to moving windows in a time series. Some studies have examined trends in moving windows by varying the start year of analysis (Wilby, 2006), whereas others have analysed moving windows of fixed length and examined trend and variance within them (Pagano and Garen, 2005; Jain et al., 2005). McCabe and Wolock (2002) proposed a methodology for visualising trends in all possible combinations of start year and end year in a time series. Variants of this approach have been applied to peak flow records in Germany (Petrow et al., 2009) and Switzerland (SchmockerFackel and Naef, 2010a), but such multi-temporal trend testing has yet to be adopted at a large-scale in Europe. Furthermore, existing applications have focused on flooding rather than a range of indicators of water resources, such as annual and seasonal flows.

This paper aims to characterise patterns of river flow variability on decadal timescales in Europe and to examine, via a multi-temporal trend analysis, the extent to which it influences observed linear trends in fixed periods. The multitemporal approach allows trends to be considered for all possible combinations of start and end dates, and is carried out for a range of different indicators of the hydrological regime (annual flows, monthly flows and indicators of extremes, i.e. high and low flow). The analysis forms a reference point, against which the results of existing (and future) studies can be assessed. The present work is a follow-up to the study of Stahl et al. (2010), which examined trends across Europe in a network of over 400 near-natural catchments using a range of fixed study periods. The study builds on the previous work by employing the same dataset, but extends the temporal coverage by examining interdecadal variability in detail. The observed trends reported in Stahl et al. (2010) have further been used as a benchmark for comparison against an ensemble of large-scale hydrological models (Stahl et al., 2012). Similarly, the present analysis could be used in the future to address how well models reproduce observed decadal-scale variability over longer timescales.

The objectives of the study described in this paper were as follows.

- Characterise decadal-scale variability in river flow (annual, monthly, high and low flows) in near-natural European catchments.

- Assess the influence of decadal-scale variability on short-term trends in fixed periods.

- Determine whether changes in recent decades are representative of the magnitude and direction of change over longer timescales.

The paper is organised as follows. Section 2 introduces the dataset and the streamflow indicators used. Section 3 describes the methodology for trend testing. Section 4 presents the results, and Sect. 5 provides a discussion of the implications of these results, followed by the concluding remarks.

\section{Data and streamflow indicators}

\subsection{Data}

This study employs a dataset of near-natural streamflow records assembled by Stahl et al. (2010), the core of which are the holdings of the European Water Archive (EWA) (see e.g. Hannah et al., 2011), but with more up-to-date data and additional data from national measuring agencies. The assembly of the dataset is described in detail in Stahl et al. (2010), with a summary of the selection criteria listed below.

- Homogeneous, quality controlled records of daily mean flow.

- Suitability for low flow analysis, including no appreciable direct human influence on river flow during low flow (e.g. through abstractions, reservoir storage).

- Small catchments with areas generally not exceeding $1000 \mathrm{~km}^{2}$ - however, some slightly larger basins were included, where there was a significant justification for improving spatial coverage.

- Time series should cover $40 \mathrm{yr}$ or longer and include recent data, at least to the year 2004.

For the present study, only those catchments with data from 1932-2004 were included in the analysis. This resulted in only 132 catchments being suitable, the majority of which are located in Scandinavia and central Europe (a map is presented in Sect. 4). This inevitably brings a regional bias into the current work which, as such, is focused on these two regions. Nevertheless, these regions provide a wide range of catchment types, and the use of this dataset ensures that the study characterises natural, climate-driven variability. There are undoubtedly other long records available in other parts of Europe (e.g. the UK, Marsh and Harvey, 2012; Ireland, Murphy et al., 2013; Finland, Korhonen and Kuusisto, 2010) that could be subjected to the same methodological approach in future studies.

\subsection{Streamflow indicators}

The following flow characteristics (indicators) were calculated based on the original time series of daily average streamflow.

- May-November AMIN7: the 7-day minimum streamflow for each year, derived for the summer period May to November.

- AMAX7: the 7-day maximum streamflow for each year.

- Monthly mean flows (January-December).

- Annual mean flows. 
The reason for choosing the May-November period for calculating low flow indicators is to ensure only summer low flows (driven by low rainfall/high evapotranspiration) are considered, and not winter low flows caused by storage in ice and snow. Mixing processes in this way would hamper the interpretation of the results.

\section{Methodology}

The overall approach to the methodology is briefly summarised here, while the following sections provide the details of the methods. Firstly, the individual catchment streamflow series were standardised, to allow comparison between sites, resulting in 132 standardised (STD) series (Sect. 3.1) for each hydrological indicator. Secondly, a locally weighted regression (LOESS) procedure was used to smooth these datasets, to emphasise variability on a decadal scale, resulting in 132 standardised, smoothed (STD_SM) series for each hydrological indicator (Sect. 3.1). Regions were then formed on the basis of homogeneous hydrological behaviour on an interdecadal timescale using cluster analysis, which was carried out on the smoothed annual mean flow series (Sect. 3.2). Regional average standardised (RA_STD) time series were then computed and subsequently used for multi-temporal trend analysis. Trend analyses were applied to RA_STD series, for all hydrological indicators, via a moving window approach encompassing all possible start/end year combinations (Sect. 3.3). Regional average smoothed (RA_STD_SM) series were also computed, primarily to display interdecadal variability, and were not used for trend analysis.

\subsection{Standardised and smoothed series}

Indicator series for each catchment were standardised by their mean value, so that on all subsequent time series plots, annual values are shown as a proportion of the longterm mean in that indicator. These are referred to as STD series, and were computed for all 132 catchments, for each indicator.

LOESS was applied to smooth the standardised series. LOESS is a robust and widely used smoothing method full descriptions of its formulation can be found in standard statistical texts on time series and trends (e.g. Chandler and Scott, 2011). The level of smoothing is dictated by a span parameter, which controls the proportion of the dataset that is used in the "local" smoothing window.

LOESS smoothing was carried out on each time series of the standardised annual mean and monthly flows as well as for AMIN7 and AMAX7 series, resulting in 132 STD_SM series for these indicators. An example of the process is illustrated for one catchment in Fig. 1, which shows a STD and STD_SM series for annual mean flows, for three different spans. Initially the standardised annual average flow dataset was chosen to investigate the ideal span factor for the
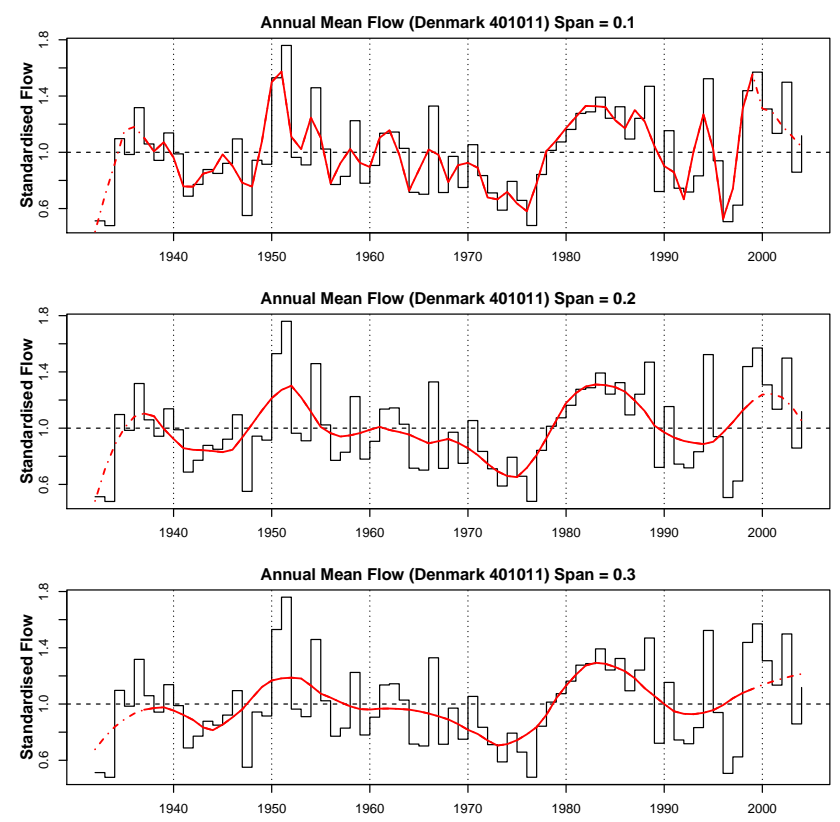

Fig. 1. Illustration of the time series calculated for individual catchments. Example of STD time series for annual mean flow for a catchment in Denmark, along with a LOESS STD_SM time series in red. Three spans are shown: 0.1 (7.2 yr), 0.2 (14.4 yr), 0.3 (21.6 yr).

LOESS smoothing. A smaller span means the smoothed series is more heavily influenced by individual points in the raw data. Span ranges of 0.1 (7.2 yr), 0.2 (14.4 yr), 0.3 (21.6 yr), 0.4 (28.8 yr) and 0.5 (36 yr) were tested on all catchments in the dataset. Visual analysis suggested a span of 0.2 best characterised the decadal-scale fluctuations within the standardised series - a span of 0.1 resulting in too much fine-scale variation, whilst spans at 0.3 and above resulted in too much smoothing.

\subsection{Construction of regions}

Regional clusters of stations were created to aid presentation and interpretation of results. As the aim was to characterise the influence of decadal-scale variability on trends, cluster analysis was carried out on the Euclidean distance matrix of all STD_SM series for annual mean flows.

Northern and central European catchments were clustered separately due to their spatial isolation. A number of clustering methods were tested including complete, partitioning and agglomerative hierarchical. Ideally, spatially coherent clusters of similar size were desired. Analysis of cluster dendrograms showed that the agglomerative hierarchical Ward method performed best in this respect, so this method was adopted. To test the sensitivity of clustering to the choice of the LOESS span parameter (Sect. 3.1), cluster analyses were performed for spans of 0.2 to 0.5 to check whether the cluster solutions varied significantly. Maps of the various cluster solutions were produced, and regional LOESS 
series were plotted for each cluster for the 0.2 and 0.3 span versions (those closest to decadal-scale variability), to check that the span parameter did not strongly influence the end results. Whilst the solutions varied in terms of individual membership, the same numbers of clusters and broad patterns emerged and the resultant regional LOESS series were consistent.

The same homogeneity metric used in the cluster analysis was computed to check the homogeneity of the clusters when used for other indicators (high, low and monthly flows). For each cluster, and for each indicator in question, the sum of the Euclidean distances between all STD_SM series in the cluster was computed, and the result was normalised by the number of catchments in the cluster.

\subsection{Multi-temporal trend testing approach}

The non-parametric Mann-Kendall (MK) statistic was used to test for trend. The application of the MK test to hydrological series has been discussed in detail by Kundzewicz and Robson (2004), and is summarised as follows.

Let us consider a sample $\left(x_{1}, \ldots, x_{n}\right)$ with size $n$. The MK statistic, $S$, is given by

$S=\sum_{i=1}^{n-1} \sum_{j=i+1}^{n} \operatorname{sign}\left(x_{j}-x_{i}\right)$.

Under the null hypothesis that there is no trend within the time series:

$$
\begin{aligned}
& E(S)=0, \\
& \operatorname{Var}(S)=n(n-1)(2 n+5) / 18 .
\end{aligned}
$$

The test statistic is the standardised value calculated as

$$
Z= \begin{cases}\frac{S-1}{\sqrt{\operatorname{Var}(S)}} & \text { if } \quad S>0 \\ 0 & \text { if } \quad S=0 . \\ \frac{S+1}{\sqrt{\operatorname{Var}(S)}} & \text { if } \quad S<0\end{cases}
$$

Typically, the hypothesis of stationarity is rejected at the $\alpha$ significance level if $|Z|>u_{1-\alpha / 2}$, where $u_{1-\alpha / 2}$ is the (1$\alpha / 2$ ) quantile of the standard normal distribution.

The MK test identifies monotonic increases or decreases in a time series by comparing between successive values, and is especially suited for non-normally distributed data, data containing outliers and non-linear trends. The MK test has been advocated for hydrological applications (e.g. Kundzewicz and Robson, 2004) and widely used in previous studies of hydrological trends at regional, national and international scales (see review by Burn et al., 2012).

The application of trend tests has been discussed widely in the literature, and in the recent past there has been some controversy over the applicability of trend tests to hydroclimatic time series (e.g. Cohn and Lins, 2005; Radziejewski and Kundzewicz, 2004; Svensson et al., 2006; Clarke, 2010). In particular, the underlying assumptions of the hypotheses of trend tests in the presence of auto and cross-correlation have been critically reviewed, and several studies have shown that streamflow series tend to exhibit long-term persistence (LTP) (e.g. Koutsoyiannis, 2003; Khaliq et al., 2009), which renders the assumptions of statistical significance testing invalid (Cohn and Lins, 2005); nevertheless, other authors have developed methods for significance testing in the presence of LTP (e.g. Hamed, 2009).

Owing to the contentious nature of this topic, and because the focus of this study is on examining the influence of decadal-scale variability on trends, testing of statistical significance was not carried out. Statistical significance depends partly on record length and on the signal-noise ratio (Wilby, 2006), so in a multi-temporal trend analysis it is more beneficial to consider the directionality or strength of trends rather than whether they exceed a pre-defined (and somewhat arbitrary) significance level. This follows the approach taken in the original study (Stahl et al., 2010). However, in the present study the MK $Z$ statistic (Eq. 3) was used as an indicator of trend, as this is less sensitive to varying record length than the trend magnitude per se.

The MK $Z$ statistic was calculated from the RA_STD time series for each indicator, for every possible combination of start and end year over the analysis period 1932-2004. Trend tests are generally less reliable for shorter periods (with at least $n=10$ recommended for the MK test); therefore, as the study focused on interdecadal variability, a minimum window length of $20 \mathrm{yr}$ was applied.

\section{Results}

\subsection{Variability in regional time series}

The result of the cluster analysis, as described in Sect. 3.2, is shown in Fig. 2. Agglomeration schedules were used to indicate the optimum number of clusters, resulting in two regions in northern and three regions in central Europe. The regions are given names that refer in a general sense to where the majority of stations are located. While the clusters are geographically coherent, there is clearly some overlap, as would be expected since they are objectively defined. The homogeneity of the regions, for each of the different indicators, is shown in Table 1.

Decadal-scale variability in each of the regions is illustrated in Fig. 3, using the RA_STD_SM time series for annual mean, high and low flows. The plots illustrate that the annual mean flow series are fairly homogeneous within each region, and the smoothed annual mean series show variability on a broadly decadal-scale, i.e. capturing decadal-length periods of above- or below-average values.

Unsurprisingly, as the clustering was performed on annual flows, the AMIN7 and AMAX7 series are less homogeneous (Table 1), although Fig. 3 demonstrates that the regional mean for each cluster provides a reasonable summary of 


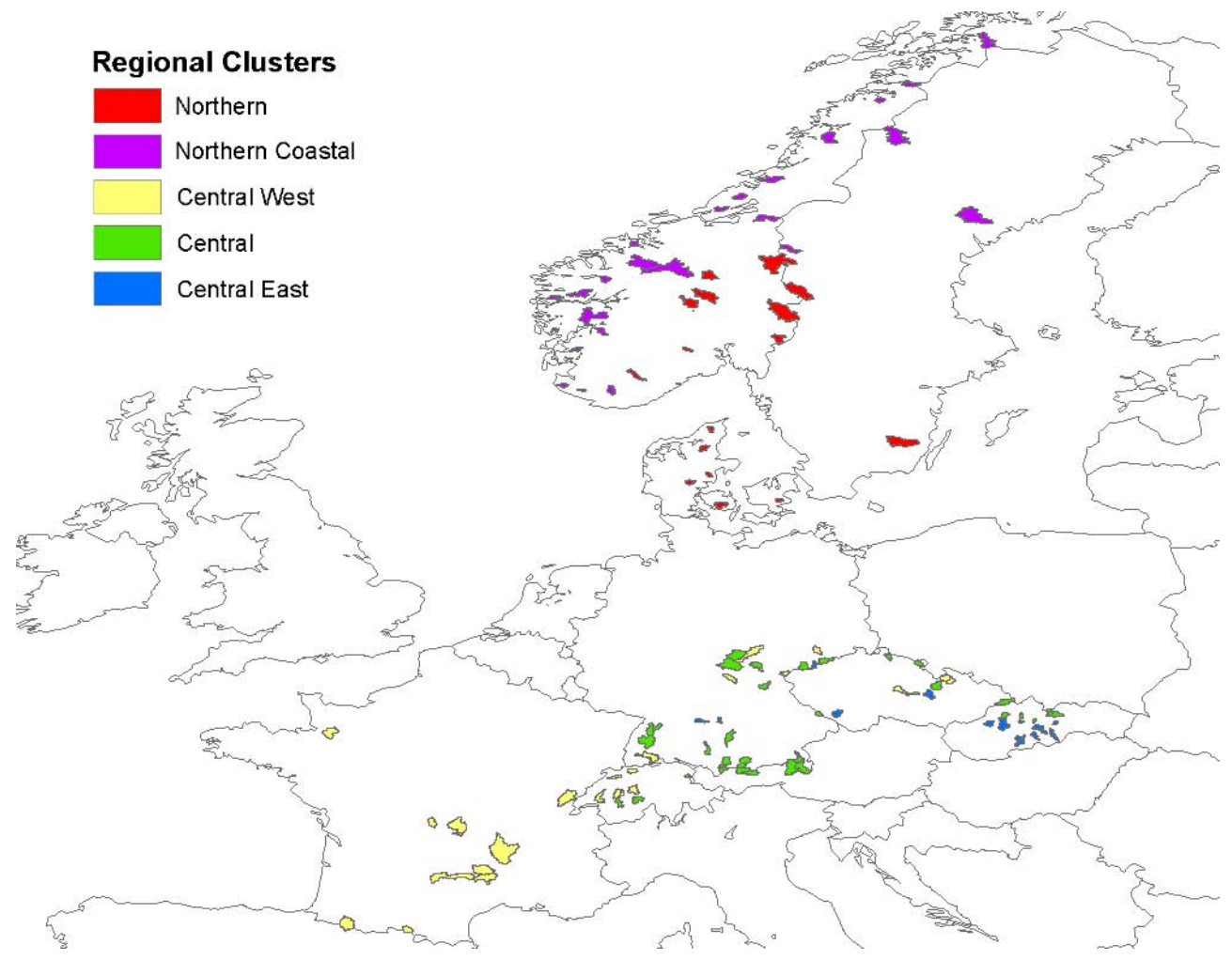

Fig. 2. Location of the catchments used, grouped into the five homogeneous regions used in this study.

Table 1. Cluster homogeneity metrics: the sum of all Euclidean distances between the LOESS STD_SM time series in each region, normalised by number of stations in the region. The metric is shown for each region/indicator combination. Smaller values indicate more homogeneous groupings.

\begin{tabular}{|c|c|c|c|c|c|}
\hline & $\begin{array}{r}\text { Northern } \\
18 \text { stations }\end{array}$ & $\begin{array}{r}\text { Northern } \\
\text { Coastal } \\
30 \text { stations }\end{array}$ & $\begin{array}{r}\text { Central } \\
\text { West } \\
27 \text { stations }\end{array}$ & $\begin{array}{r}\text { Central } \\
38 \text { stations }\end{array}$ & $\begin{array}{r}\text { Central } \\
\text { East } \\
15 \text { stations }\end{array}$ \\
\hline $\begin{array}{l}\text { Annual } \\
\text { Mean }\end{array}$ & 9.1 & 13.5 & 18.3 & 18.3 & 14.5 \\
\hline AMIN7 & 27.6 & 44.6 & 34.4 & 33.9 & 22.0 \\
\hline AMAX7 & 14.4 & 18.1 & 29.7 & 30.8 & 20.9 \\
\hline Jan & 19.4 & 38.9 & 30.7 & 35.6 & 23.9 \\
\hline Feb & 24.2 & 43.9 & 31.8 & 34.6 & 24.7 \\
\hline Mar & 24.9 & 50.0 & 28.5 & 32.0 & 22.3 \\
\hline Apr & 23.1 & 37.5 & 31.0 & 33.8 & 19.1 \\
\hline May & 18.9 & 27.9 & 33.2 & 38.9 & 21.2 \\
\hline Jun & 24.7 & 30.8 & 38.0 & 36.4 & 22.3 \\
\hline Jul & 31.1 & 37.5 & 46.8 & 49.5 & 32.2 \\
\hline Aug & 33.0 & 40.1 & 41.6 & 44.6 & 29.5 \\
\hline Sep & 28.2 & 31.8 & 50.9 & 43.9 & 28.1 \\
\hline Oct & 23.3 & 31.0 & 48.8 & 40.1 & 33.6 \\
\hline Nov & 21.9 & 32.7 & 38.6 & 37.8 & 25.0 \\
\hline Dec & 25.6 & 38.3 & 37.7 & 39.4 & 25.5 \\
\hline
\end{tabular}

interdecadal variability across the various catchments. Generally, for these indicators, the regional mean captures periods where most stations are similar in showing either positive or negative flow anomalies, although in some regions there are some time series (but generally few) that show variations which are out-of-phase with the regional average. As would be expected, the homogeneity is better in Central East, with only 15 stations, compared to Central, with 38 stations, and generally the homogeneity for AMAX7 is better than for AMIN7 (with the Northern Coastal region showing lower homogeneity for AMIN7 in particular). Similarly, for monthly averages cluster homogeneity is generally good, although varies across regions and throughout the year. The lowest homogeneity is for the Northern Coastal region in winter. All regions (except Northern Coastal) tend to have lower homogeneity in late summer, with the lowest homogeneity at this time in the Central West and Central East regions. The corresponding LOESS plots for monthly flows are shown in the Supplement.

Overall, Table 1 and the plots in Fig. 3 and the Supplement suggest that the regions are reasonably homogenous in terms of their interdecadal variability, and therefore average time series for these regions are considered a good basis for performing multi-temporal trend analyses. An alternative approach would be to form regions for each indicator (AMIN7, AMAX7, and each of the 12 months); undoubtedly, these regions would be more homogeneous, but the benefit of doing so would be outweighed by the disadvantage of having 15 different cluster solutions, which would severely hamper interpretation of the results. Thus, a pragmatic decision was made to use regions formed on the basis of annual mean 


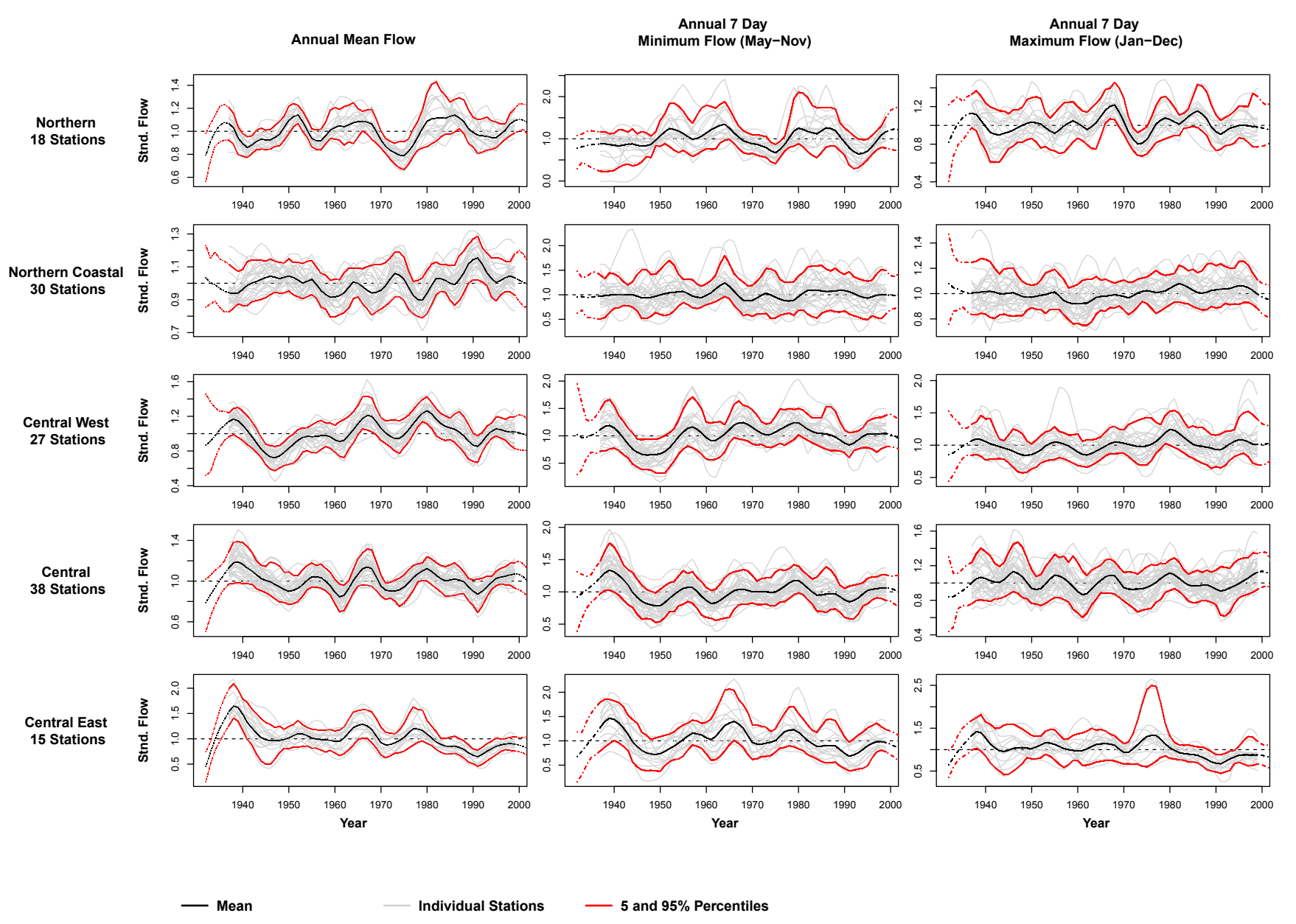

Fig. 3. Interdecadal variability derived using LOESS smoothing. Grey lines show individual station STD_SM series, black line shows RA_STD_SM series. Red lines show the 5th and 95th percentiles of the combined STD_SM series.

flows, with the above analysis confirming that the regions can be expected to be reasonably homogeneous for the other indicators.

As described in Sect. 3.1, the RA_STD_SM series are used to characterise interdecadal variability, whereas the RA_STD series are used in the trend analyses. The RA_STD series are shown in Fig. 4 (using the same scheme as Fig. 3). The range of variation in the RA_STD series is obviously lower than in the full set of component STD time series but this is unlikely to affect the trend testing using the MK statistic, which is based on successive differences between observations rather than absolute magnitude.

\subsection{Multi-temporal trends in annual flows and high and low flows}

The multi-temporal trend analysis results for annual mean, low (AMIN7) and high (AMAX7) for all regions are shown in Fig. 5. There are clearly substantial differences between the regions, and in the directionality and magnitude of trends over time for any one region, which are discussed below.
For the Northern region, annual flow trends are predominantly positive (towards wetter conditions) across most periods, although trends from the early period ending in the late 1970s/early 1980s are negative (towards drier conditions). All trends ending in the mid-1980s onwards are positive, with the strongest positive trends starting in the 1970s and ending in the 1990s/2000s. Overall, stronger trends are found for AMIN7 and they follow a very different pattern: trends from the early decades up to the 1970s are strongly positive, and those starting pre-1940 remain positive up to the 1980s and 1990s. In contrast, trends starting between 1940 and 1960 are mostly negative, for all end dates, and particularly strong when ending in the mid-1970s and mid-1990s. These periods of lower than average annual flow and AMIN7 are clear in the decadal-scale variability plots (Fig. 3) and correspond to periods with notable droughts in southern Scandinavia (e.g. Zaidman et al., 2002; Hannaford et al., 2011; Parry et al., 2011). Weak trends are found for AMAX7, and the patterns lack coherency. Although positive trends are 


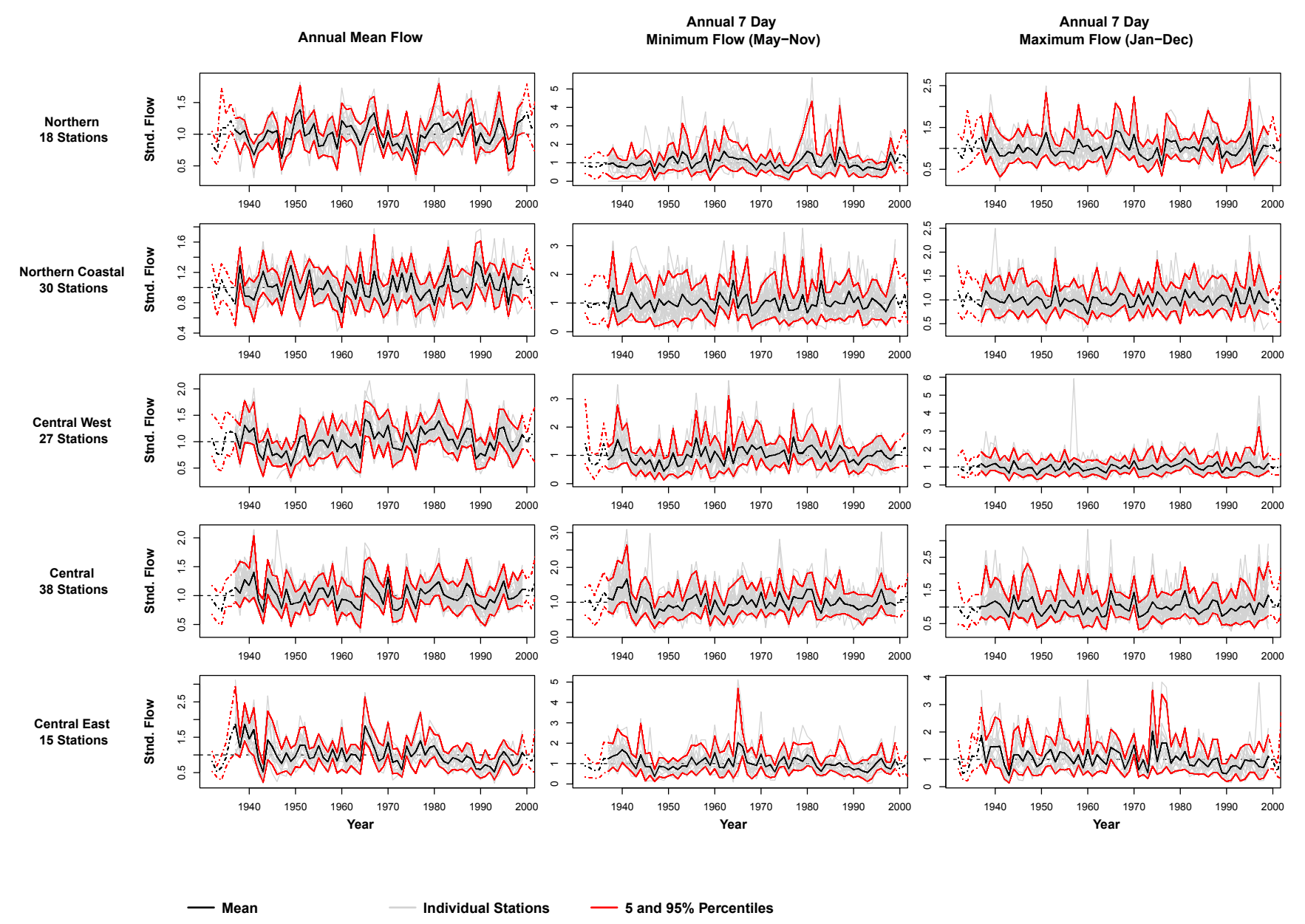

Fig. 4. Variability in RA_STD time series (black) and individual STD time series (grey). Red lines show the 5th and 95th percentiles of the combined STD series.

more apparent, there are fluctuations between positive and negative trends over a range of periods.

Within the Northern Coastal region, there is a very strong contrast in trend directionality over the annual mean series. Trends starting in the first few decades are all negative up to the 1990s (although trends are relatively weak). In contrast, all trends ending after 1990 (from any start year) are positive. The AMAX7 series is similar, except the shift towards positive trends starts earlier (in the 1980s) and there is a recent downturn; trends starting after the 1960s and ending after 2000 are weakly negative. For AMIN7 the pattern is different, showing positive trends from the early and later decades, and negative trends in between - but the trends are rather weak. The AMIN7 pattern resembles that for the Northern region, but with much weaker trends.

The Central West region also shows strong contrasts over time, and some of the strongest trends observed in the study. All three indicators follow the same pattern, but with subtle variations. For annual flows, trends are predominantly positive (and strong for some periods), except for trends in the earliest period (ending in the 1970s) and trends starting around 1955 onwards and ending after 1990. That is, there is a shift from generally decreasing trends to strong positive trends, and back to decreasing trends after about 1955. The positive trends are strongest when starting between the 1940s and 1950s. For AMIN7 the pattern is similar, but the recent downturn starts earlier (1950) and negative trends are locally stronger (e.g. from the 1960s ending in the 1990s). A similar pattern is seen for AMAX7 but the early period of negative trends is longer, and the later period of negative trends is shorter. The similar patterns of time-varying trends seen across all indicators are unsurprising given the interdecadal fluctuations which are apparent in this region (Fig. 3). A long period of below-average flows is apparent (most obvious in annual and AMIN7) from the early 1940s until the mid1950s; this undoubtedly causes positive trends starting from these years, whereas trends starting from the higher flows of the 1960 s are, unsurprisingly, negative. The 1940s was a period of notable precipitation deficits associated with major 


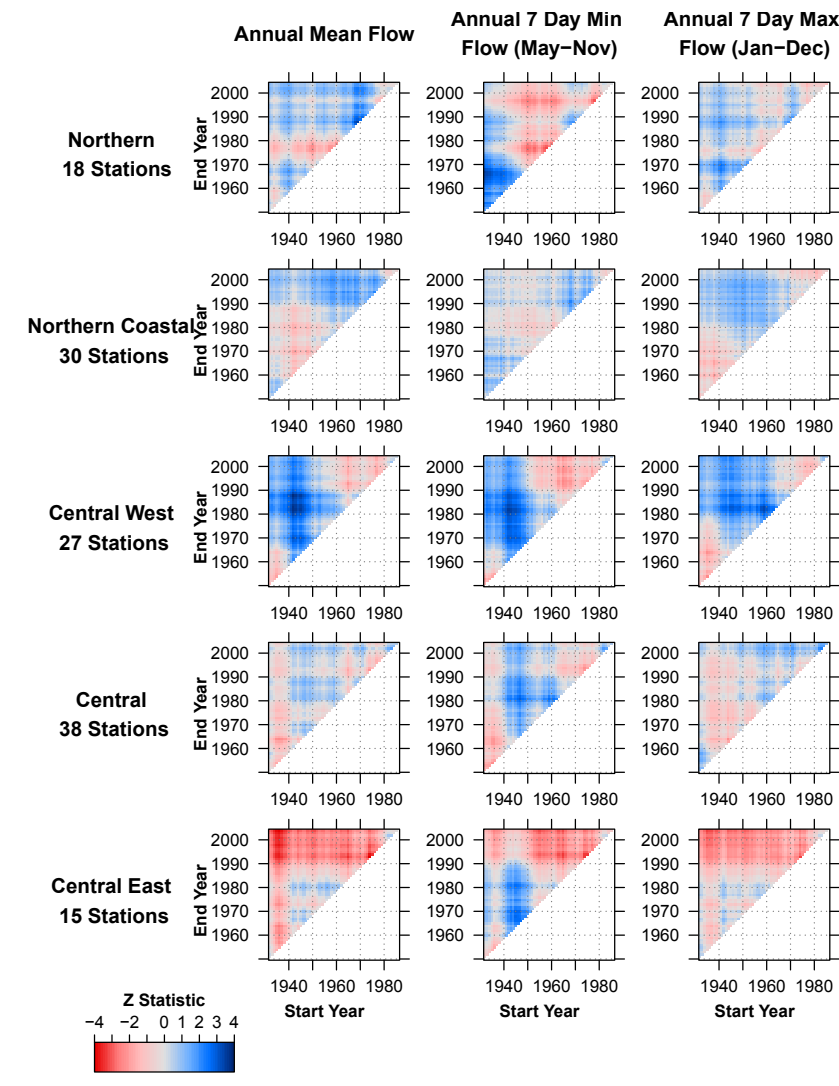

Fig. 5. Multi-temporal trend analysis for annual mean, AMIN7 and AMAX7. x-axis shows start year of trend, y-axis shows end. The MK test applied to all start and end years, and the corresponding pixel is coloured according to the resulting $Z$ statistic (see legend), with red representing negative trends, and blue representing positive trends.

droughts in France (see the European Drought Catalogue published by Parry et al., 2011).

For the Central region, the annual trends are generally weak and mixed, with no coherent patterns of positive or negative trends. Both the annual flows and AMIN7 show similar patterns, although for AMIN7 trends starting between 1940 and 1960 are mostly positive, across all end dates, and stronger (e.g. ending in the 1980s). In contrast, trends starting pre-1940 are negative across all end dates; likewise, trends starting after the 1960s are generally negative. For AMAX7 the picture is different; trends starting pre-1955 are negative (although weak) across all end dates, with post-1960 trends being more mixed; trends ending after 2000 are generally positive.

The Central East region shows the strongest negative trends and the least sensitivity to changing study period. Irrespective of start year, all annual flow trends ending after 1990 are negative (and mostly strong). Most trends in the earlier series are also negative, although weaker and more mixed, with some local positive trends. The pattern for AMAX7 is very similar, but with slightly weaker negative trends. For
AMIN7, trends ending after 1990 are also generally negative; however, before this there is evidence of strong positive trends in periods starting from the 1940s and ending up to 1990. The tendency towards negative trend patterns in this region can be viewed in the context of the long-term variability shown in Fig. 3. For all indicators, the end of the series is characterised by below average conditions after 1980. Early periods were generally at or above average (especially in the mid-1960s and mid-1970s), and the pre-1940 flows were also high. The positive trends in AMIN7 are clearly influenced by some lower than average conditions in the late 1940s.

Some general observations can be made across all regions and indicators. Firstly, there are clearly parallels between the patterns observed between regions (e.g. between AMAX7 in the Northern Coastal and Central West regions). Secondly, there is no unique relationship in Fig. 5 between trends in the mean and trend patterns in the extremes, although clear similarities exist; in general the high flow patterns resemble the mean more than low flows, which is unsurprising given the typically skewed distribution of streamflows. Low flow trend patterns can be very similar to the mean (e.g. Central East region) or a different pattern (e.g. Northern region). Generally, however, trends in high and low flows resemble the trend in the mean annual flow, and this is borne out by strong correlations between the RA_STD annual series and the high and low flow series, respectively, as shown in Table 2. Overall, therefore, a trend towards wetter average conditions implies an increase in high and low flows; similarly, a trend towards drier conditions implies decreasing high and low flows. This is also reflected in the significant positive (albeit weak) correlation between high and low flow series.

\subsection{Multi-temporal trends in monthly flows}

For both Northern regions (Fig. 6), the patterns for the winter months are broadly similar: generally, there is a contrast between a higher prevalence of negative trends in the earlier decades, up to the 1990 s, and generally positive trends ending post-1990 (from any start date). The timing of this shift, and the strength of the contrast between positive and negative trends, is highly variable between months - with December showing generally weak trends in both regions, and the strongest contrast being for January in the Northern region. In spring, the general pattern is fairly similar between the two regions, albeit with substantial differences in timing and trend magnitude. March and April are similar to the winter pattern, with a particularly strong contrast between early negative trends and later positive trends in April in the Northern Coastal region. May is completely different, and almost reversed; with a contrast between positive trends for nearly all study periods, and negative trends when starting post-1960s/1970. The May pattern is indicative of a downturn late in the series, which starts much later for the coastal region. 
Table 2. Spearman's rank correlation coefficient between the annual (Ann), high flow (AMAX7) and low flow (AMIN7) RA_STD series (all values are significant at $p<0.05$ for a two-tailed test, where the critical threshold is $r>0.236$ ).

\begin{tabular}{llr}
\hline & & Spearman's $r$ \\
\hline Northern & Ann vs. AMIN7 & 0.66 \\
& Ann vs. AMAX 7 & 0.61 \\
& AMIN7 vs. AMAX 7 & 0.25 \\
\hline \multirow{2}{*}{ Northern Coastal } & Ann vs. AMIN7 & 0.59 \\
& Ann vs. AMAX 7 & 0.73 \\
& AMIN7 vs. AMAX 7 & 0.28 \\
\hline \multirow{2}{*}{ entral West } & Ann vs. AMIN7 & 0.77 \\
& Ann vs. AMAX 7 & 0.70 \\
& AMIN7 vs. AMAX 7 & 0.37 \\
\hline \multirow{2}{*}{ Central } & Ann vs. AMIN7 & 0.76 \\
& Ann vs. AMAX 7 & 0.79 \\
& AMIN7 vs. AMAX 7 & 0.44 \\
\hline Central East & Ann vs. AMIN7 & 0.74 \\
& Ann vs. AMAX 7 & 0.85 \\
& AMIN7 vs. AMAX 7 & 0.55 \\
\hline
\end{tabular}

Summer trends for the Northern region are rather mixed: June and July show generally weak trends, with shifts between positive and negative tendencies, but August shows stronger patterns of mostly negative trends except for the earliest periods and those starting after 1970. For the Northern Coastal region the months are very different: June trends are mostly negative, with particularly strong decreases ending in the late 1980s/early 1990s, whereas July and August show mostly weak trends, with July showing negative trends ending in the 1990s (similar to June) and positive trends elsewhere, and August showing similarities to the patterns observed in winter. Autumn months also show pronounced differences between months and between the two regions. For the Northern region September trends are largely negative, except for trends with early start dates ending pre-1970, and trends starting around 1970 (for any end date); October and November are similar, with generally weak and mixed trends. For the Northern Coastal region September trends are generally positive, except those ending around 2000; October trends are rather weak and negative, whereas November trends are weak and mixed.

Figure 7 shows pronounced contrasts between the three central regions. The Central West region has many months showing a broadly similar pattern not unlike that for annual flows. This pattern is strongest in spring/early summer (April-June), which shows a strong contrast between positive trends for periods except those starting after 1960, which are mostly negative. The negative trends are stronger and start earlier in June, and this pattern intensifies in August, which has very strong trends for most periods when ending after
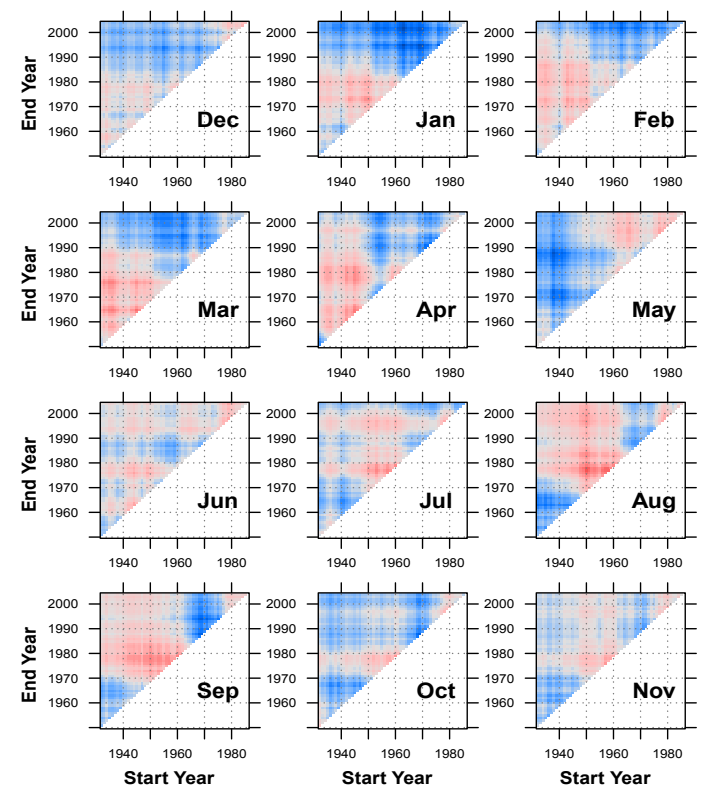

Z Statistic
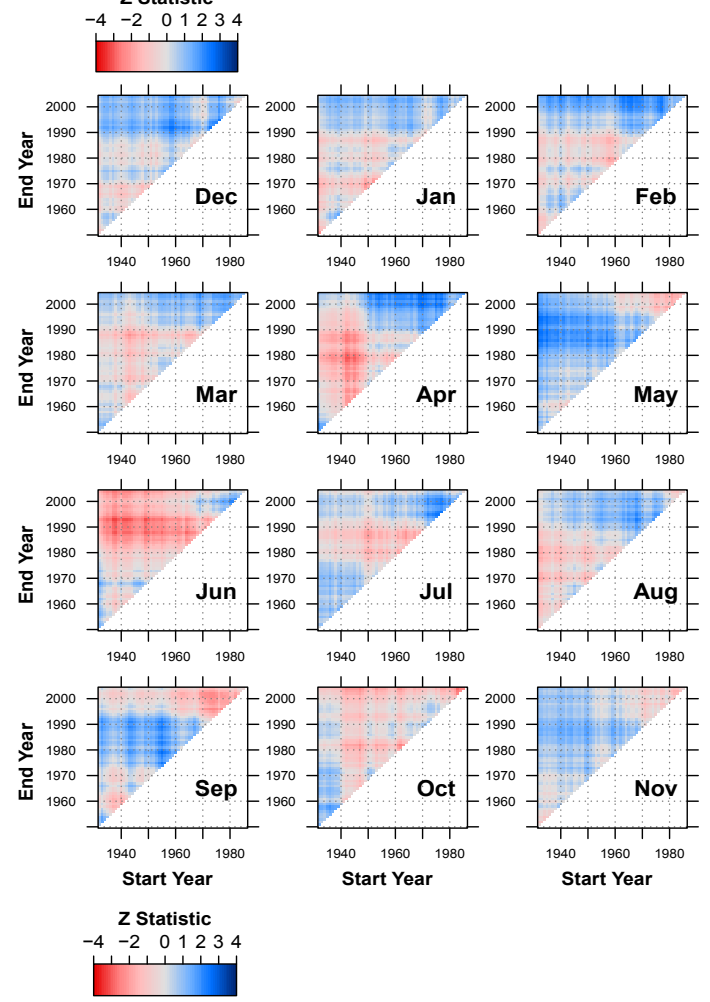

Fig. 6. Multi-temporal trend analysis for individual months for (top) Northern and (bottom) Northern Coastal regions. Explanation as for Fig. 5.

1990. The winter months show some signs of the characteristic pattern seen in the annual trends, but the contrast is muted and trends are weak; autumn trends were also rather weak and mixed. 

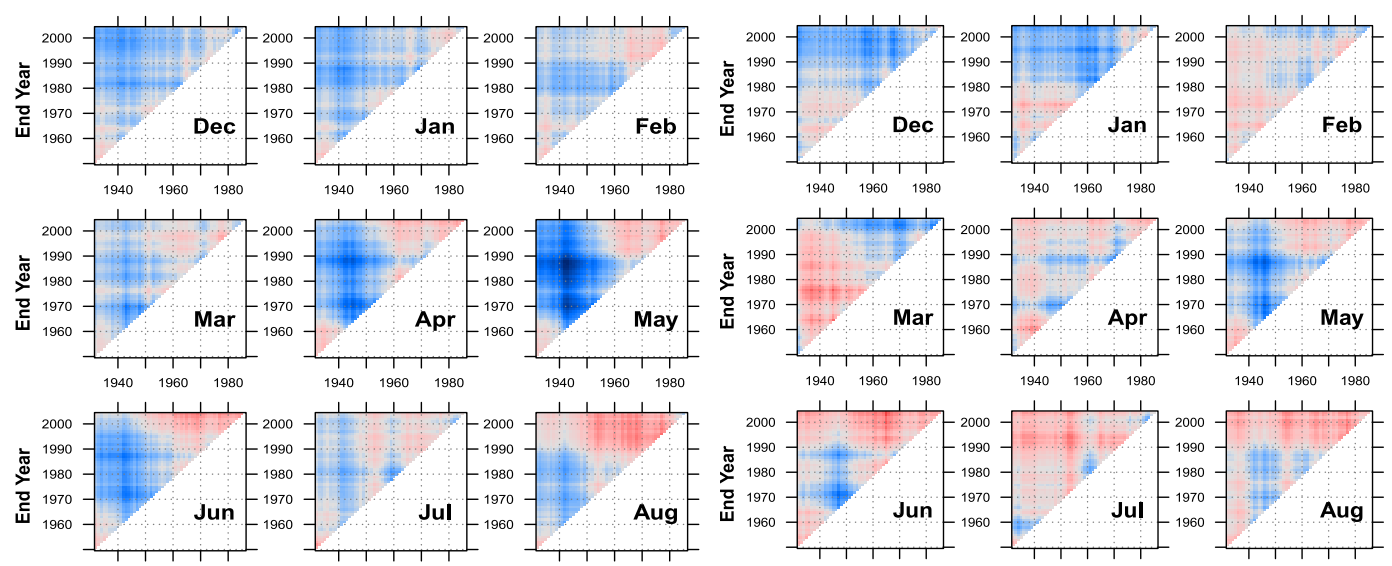

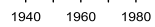

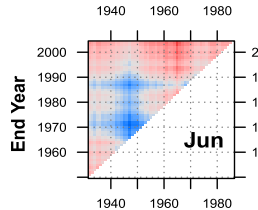

$\underset{1940}{1} \int_{1960}^{1} \quad \frac{1}{1980}$
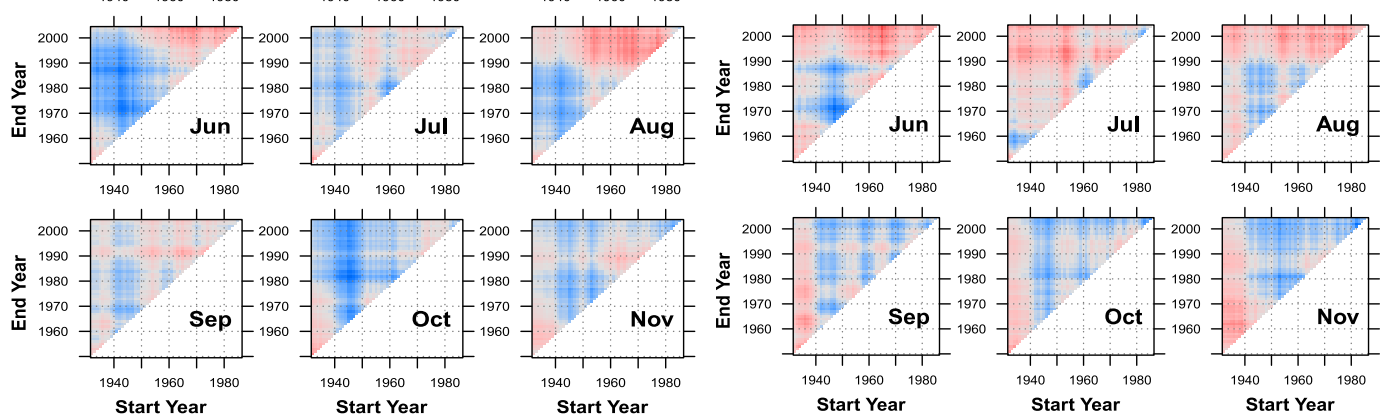

$Z$ Statistic

$\begin{array}{lllll}-4 & -2 & 0 & 1234\end{array}$
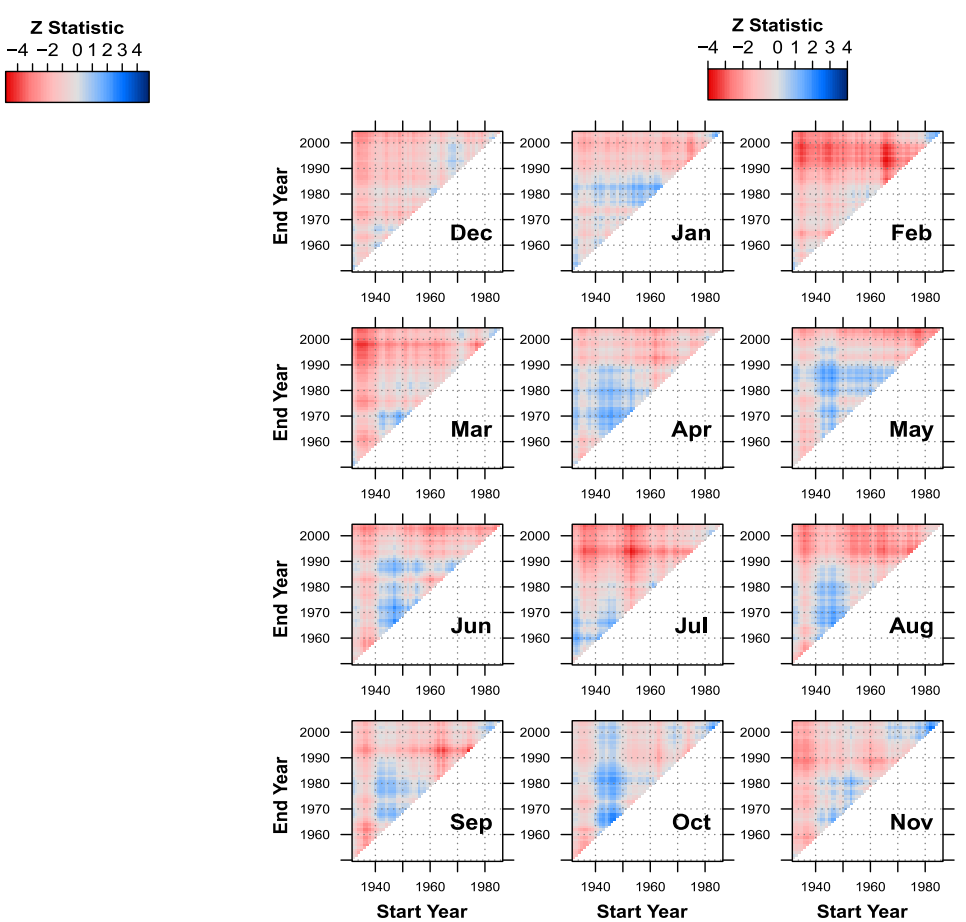

Z Statistic
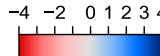

Fig. 7. Multi-temporal trend analysis for individual months for (upper left) Central West, (upper right) Central and (bottom) Central East regions. Explanation as for Fig. 5.

The Central region shows mixed patterns between months. Winter trends are weak, but December and January show a contrast between negative trends in early periods with recent positive trends, contrasting with very weak February patterns. The spring patterns are similar to patterns in the northern regions: namely, recent March increases, following early decreases, contrasting with the opposite in May. Summer trends are variable, but with a prevalence of negative trends for end dates near the end of the series, and more mixed patterns earlier. September and October show a mix of positive and negative trends, whereas November trends are positive, except those starting pre-1940. 


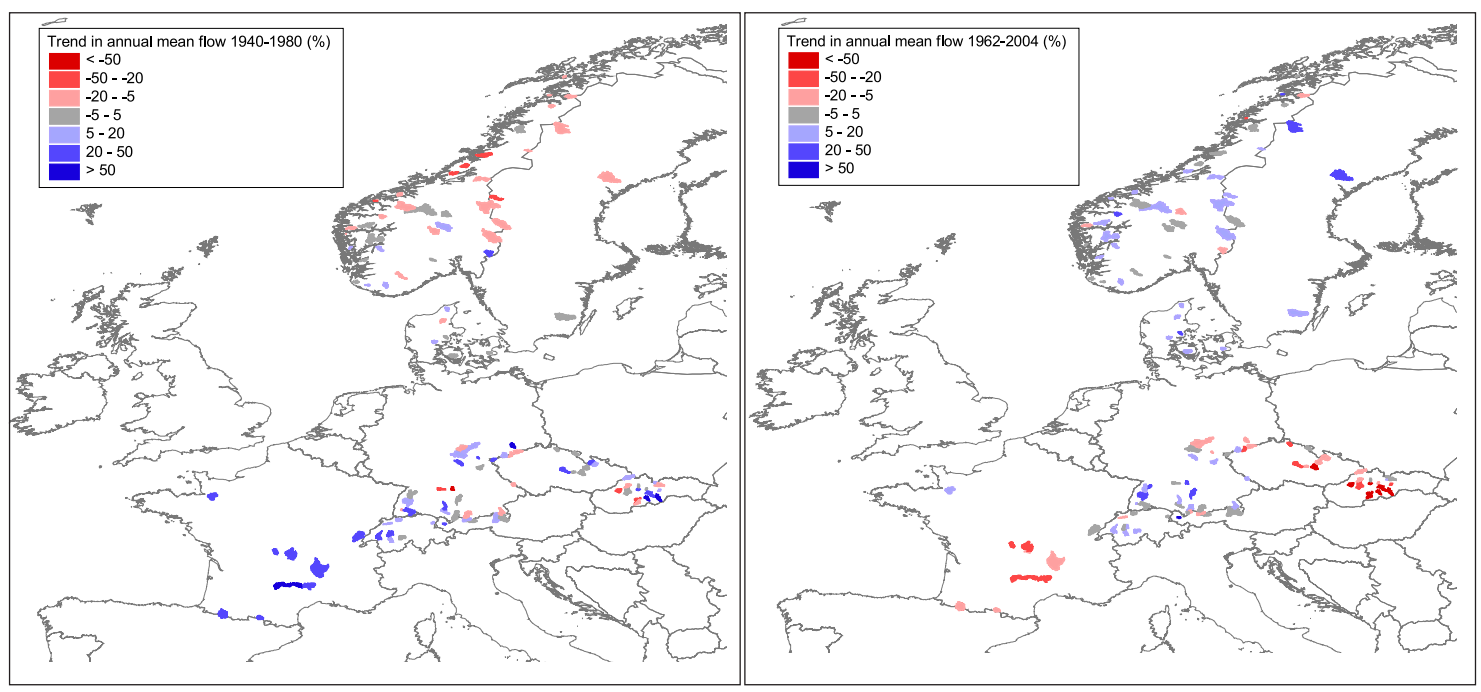

Fig. 8. Comparison of trends in annual mean flow for the fixed 1940-1980 period with the 1962-2004 period (using the same trend testing approach as Stahl et al., 2010).

As with annual flow indicators, monthly flows for the Central East region all show a predominant tendency towards drying trends, which is fairly resilient to study period: these are the strongest negative trends seen across all regions. Whilst negative trends predominate across study periods, they are strongest in the more recent period, in particular for periods ending post-1990, across most months; strongest decreases are for late winter through to the summer, especially for February, March, July and August. For earlier periods, trends were generally weaker and sometimes positive (e.g. from the 1940s/1950s up to the 1980s in April and May).

\section{Discussion}

The results of the current study complement Stahl et al. (2010), and provide a context within which to compare the results of that paper. Stahl et al. (2010) found evidence of a decrease in annual mean, summer mean and low flows across much of eastern and southern Europe, over the 19622004 period, in contrast to an increase in annual mean and winter flow in northern Europe. Herein, in the Central East region the comparable recent (post-1960) negative trends accord with a tendency towards decreasing flow that persists over the full record (1932-2004). In contrast, in the Central West region, post-1960 negative trends are not seen in longer periods, which show an increase in runoff from the 1940s up to 2004. Clearly, the decadal-scale fluctuations shown in the long series lead to periods of above (below) average flows, and their relative positioning can influence monotonic trends. In the case of the Central West region, a very long, dry period occurs early in the record, whereas in the Central East region the driest period occurs near the end of the series. Such "clus- tering" of below average years at least in part explains the difference between the two regions. Similarly, in the two northern regions, post-1960 increases found by Stahl et al. (2010) are not necessarily representative for other periods: if records ended around 1990, calculated trends would have been primarily negative, so the recent past has had a strong influence on long-term trends.

These findings beg the question: how representative is the finding of decreasing river flows from 1960 to 2004 in southern/eastern Europe as reported by Stahl et al. (2010)? They suggest that the large-scale dipole between increasing flows in the north and decreasing in the south is consistent with climate change projections (though this in itself does not amount to attribution). The results shown here demonstrate that this pattern is less obviously apparent, or even contradicted, if different sub-periods were used. For example, Fig. 8 shows the results for the $1940-1980$ period. From this perspective, flows would have been observed to increase in France, and decrease in northern Europe, a reversal of the dipole-like pattern. But that period is less relevant from a climate change perspective, being that Northern Hemisphere temperatures have increased most markedly from the post1980 period (IPCC, 2007). The widely adopted (due to data availability) post-1960 period yields different results compared to earlier and later start years. The rest of this section considers these findings in the context of other work and discusses potential drivers of observed fluctuations and associated trends.

The general drying seen in recent years in southern and eastern Europe by Stahl et al. (2010) relied on a sparse network. However, in a follow-up study, Stahl et al. (2012) used an ensemble modelling approach (validated using observed streamflow trends of the original study) to show that the 
negative trends observed are part of a much wider pattern of decreasing runoff in eastern and southern Europe. Unfortunately, the network used in the current study is even sparser than in Stahl et al. (2010) owing to the paucity of long records, which limits the potential for assessing how representative these recent drying trends are of longer timescales in southern Europe.

Nevertheless, recent flow decreases reflect a longer-term decrease of river flows (including high and low flows) in the eastern catchments (primarily Slovakia) studied here. Other river flow trend analyses also show decreasing flows, e.g. decreases in summer flow from the 1940s-1990s in Slovakia (Majercakova et al., 1997) and decreases in summer low flow in the Czech Republic from the 1961-2005 (Fiala et al., 2010) (note however that the Czech Republic includes stations from all three Central regions in the present study). Moreover, a long-term drying in eastern Europe has been found in studies of rainfall (e.g. Bordi et al., 2009; Trnka et al., 2009).

In the Central West region studied here (primarily southern France), in contrast, the recent flow decreases shown in Stahl et al. (2010) are not seen in longer periods. A similar finding was observed by Giuntoli et al. $(2012,2013)$ who found decreasing annual flows, high flows and low flows in southern France over the 1968-2008 period, contrasting with increasing trends from 1948-1988. The extended drought conditions of the 1940s in France (Parry et al., 2011) are likely influential, but the question remains as to what has driven these patterns of interdecadal variability. Giuntoli et al. (2013) found correlations between annual/low flows and the NAO in this area. River flow trends were sensitive to study period, but relationships with the NAO were not, so this driver may be responsible for long-term river flow fluctuations; although the NAO influence was variable between seasons. Interestingly, in the present study, the monthly patterns which correspond most closely to the annual flow patterns (of a shift from positive to negative trends) in the Central West region are for spring and early summer. A similar pattern of decreasing spring flows in the last $30 \mathrm{yr}$, contrasting with increasing trends from longer periods, has been found in the UK (Hannaford and Buys, 2012) and Ireland (Murphy et al., 2013). Future work should examine these parallels in more detail, to establish to what extent they reflect large-scale changes over Western Europe driven by atmospheric circulation. Recent decreases in spring rainfall across Western Europe have been linked to the transition to the warm phase of the Atlantic Multi-decadal Oscillation (AMO) in the mid-1990s, following the previous cool phase (Sutton and Dong, 2012).

In the Central region, the results of the multi-temporal analysis revealed very mixed patterns over time, and generally weak trends. This may partly reflect the heterogeneity of this region, in terms of terrain and hydrological processes, which embraces mountainous parts of southern Germany, Switzerland and Austria. This region also saw very variable spatial patterns of trends in Stahl et al. (2010), and was one of
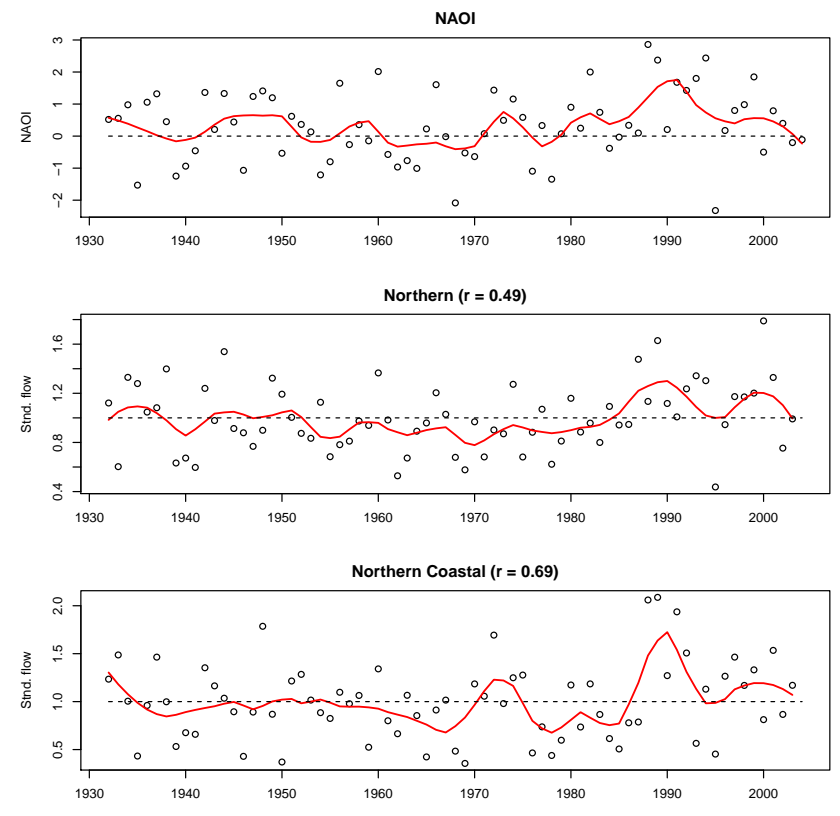

Fig. 9. Time series plots and LOESS smoothing lines for the December-March NAOI and December-March average flow for the two northern regions. Spearman's rank correlation coefficient between winter flows and NAOI is shown.

the most challenging regions for model reproduction of observed trends (Stahl et al., 2012). Similarly, very mixed trend responses were observed across the Alpine ranges by Bard et al. (2011, 2012). Nevertheless, there is a good degree of homogeneity in annual flows (Fig. 3), and the series is characterised by marked decadal fluctuations about a relatively stable mean, which lead to the very mixed patterns of (generally weak) positive/negative trends, with no overall change over the 1932-2004 period, as seen for the other indicators. This echoes other studies which have also found evidence for marked variations between wetter and drier periods in this region (e.g. Petrow et al., 2009; Schmocker-Fackel and Naef, 2010a; Villarini et al., 2011). However, there is a tendency towards wetter winters in more recent years, and increased high flows, which accords with the findings of Petrow et al. (2009) for southern Germany. Conversely, low flows and summer flows show mixed results, but the tendency towards recent drying accords with various climate studies that have observed significant summer drying and warming trends (e.g. van der Schrier et al., 2007).

In the Northern and Northern Coastal regions, the increase in flow post-1960 is sensitive to study period. For both regions, the trends in annual flows are strongly influenced by decadal variability, with decreases early in the records contrasting with later increases. This contrast is suggestive of variability in the NAO, known to influence rainfall and river flows in northern Europe (e.g. Bouwer et al., 2008; Wrzesiński and Paluszkiewicz, 2010). A similar pattern is prevalent in winter, the period over which the NAO 
association is strongest (typically, the winter NAO is characterised over December-March). Figure 9 illustrates variations in the NAO Index (NAOI) alongside the changes in December-March flows for the two northern regions. The relationship suggests that the trend patterns seen in winter (and to a lesser extent in annual and high flows) - i.e. decreases from the 1930s to the 1970s, and a strong increase thereafter - may reflect low-frequency variability in the NAO. The interdecadal patterns of variability are congruent but there are departures on an interannual timescale. Clearly, the NAO is not the only large-scale driver of winter river flow, and other large-scale patterns such as the Scandinavia pattern have been shown to influence winter flooding (e.g. Lavers et al., 2012) and drought (e.g. Hannaford et al., 2011) occurrence in northern Europe.

One of the challenges of interpreting trends in the northern regions is the complexity of hydrological processes which operate in these cold climates. River flow is influenced by changes in temperature, in addition to precipitation, particularly in winter and spring when water is stored as snow and subsequently released through melt. One interesting feature to emerge from this study is the temporal change seen in the spring/early summer months in both northern regions. The recent increases in April, and decreases in May (and June) may reflect earlier snowmelt in these regions. A tendency towards earlier dates for the spring snowmelt peak has been observed for Scandinavia (Wilson et al., 2010), and is likely driven by increasing temperatures causing earlier melt. Broadly similar trend evolution patterns (comparing March to May) can be seen for the Central region, which has numerous high-elevation catchments and may also therefore be experiencing similar snowmelt changes. Bard et al. (2012) also found evidence for earlier snowmelt flooding across the Alpine range. Further work is required to investigate these findings, for all cold/alpine regions, in the context of observed changes in spring temperature and winter snowfall. Verpe-Dyrdall et al. (2013) found long-term decreases in winter snow depth in coastal regions of Norway, related to increased winter temperatures.

A final observation is that the decadal-scale fluctuations seen in the long records have some consistency between regions. The regions are introduced to simplify interpretation, but like any cluster analysis they are a statistical construct, and similar decadal fluctuations may exist across large parts of Europe. Whilst the sequencing and timing of fluctuations varies between the regions, the overall oscillations are similar; all regions have below-average annual flows in the mid-late 1970s, for example, a period of spatially coherent drought across a large area of Europe (Zaidman et al., 2002; Hannaford et al., 2011). Synchronous patterns of lowfrequency climate variability across large parts of Europe (driven by, e.g. the NAO or AMO) will undoubtedly transcend the boundaries of the regions used herein. Some of the differences between regions may reflect the extent to which the same large-scale circulation patterns are modulated by catchment storages, which control the relative importance of low frequency (decadal) and high frequency (inter- and intraannual) scales of variability (e.g. Gudmundsson et al., 2011).

Within regions, there is also a good degree of coherency between the indicators of annual, high and low flows, implying that these components of the regime tend to vary broadly in tandem with each other. In the long series used in this study there is, thus far, little evidence of the divergence between annual dry and wet extremes (i.e. wet getting wetter, and dry getting drier) that may be expected in a warming world (e.g. Giorgi et al., 2011). However, the present study employs annual indicators (AMAX7 and AMIN7) of "high" and "low" flow rather than true extremes, so further investigation is needed to explore the coherency of wet and dry extremes in future. In the western USA, some studies have reported increasing interannual variability in streamflow, using moving window approaches (Jain et al., 2005; Pagano and Garen, 2005), and divergence between wet and dry ends of the annual streamflow regime, using quantile regression (Luce and Holden, 2009). Similar approaches could be applied in future to the dataset used herein, to examine changing distributional properties of the regime as a whole, rather than separate indicators.

A more complete set of long records from across Europe (and ideally embracing records starting before 1932) would enable an improved characterisation of spatio-temporal variability in streamflows on decadal scales, better identification of patterns of synchronous drought or flood, and thus an improved basis for linking hydrology to climate drivers. In particular (echoing the call made in Stahl et al., 2010, for more streamflow data in southern regions) we underline the importance of carrying out long record analyses in southern and eastern regions of Europe where data are sparse at present. More long-term data is needed to determine whether recent tendencies towards decreased runoff in the Mediterranean (Stahl et al., 2012) are seen in longer records (as in the Central East region) or not (as in Central West), and whether this is related to atmospheric circulation. A general trend towards drying has been observed across the Mediterranean (Sousa et al., 2011) and streamflows in Iberia have decreased from 1945 to 2005 (Lorenzo-Lacruz et al., 2012). However Mediterranean precipitation and streamflows are also known to be influenced by the NAO (e.g. López-Moreno and Vicente-Serrano, 2008; Lorenzo-Lacruz et al., 2011). The shift towards a positive NAO, which can be linked to increased river flow in northern Europe post-1960, would be expected to imply decreased runoff in southern Europe. More long-term data is needed to clarify the extent to which the large-scale dipole in runoff changes, with increases in the northwest and decreases in the southeast (Stahl et al., 2010, 2012), is consistent with climate change, variability associated with the NAO, or a combination of both (as the NAO may itself respond to anthropogenic forcing, e.g. Dong et al., 2011). 


\section{Concluding remarks}

The results of this study demonstrate considerable variability of trends in time. A fixed study period represents just one pixel in the multi-temporal trend plots shown here. The variation in trend strength and direction across these plots suggests that an extrapolation of the trend is not justified in most cases and extrapolation (into past or future) of such a selective viewpoint could easily be misleading. This echoes the concerns raised by previous authors (e.g. Svensson et al., 2006; Chen and Grasby, 2009). This study has gone further, by attempting to elucidate exactly how interdecadal variability manifests itself across a large area of Europe, and how this influences short-term trends. It thus provides a foundation for indexing the sensitivity of trends to study period for a range of existing studies.

This study has demonstrated that the multi-temporal trend testing approach used here (based on a method originally formulated by McCabe and Wolock, 2002) is a powerful one. Fixed periods are essential for trend analyses - to facilitate mapping and quantification of trends on a regional scale - and their position in the statistical toolkit for hydroclimatology is likely to be a fixture in future, especially given that most hydrometric records are short. We therefore advocate the added value of balancing the findings from shortterm periods with a separate multi-temporal analysis; that is, complementing a short, fixed period network with a high spatial density (in order to capture regional trend patterns), with a multi-temporal analysis using the longest available records - even if the latter are few in number.

One obstacle, however, is that long records are rare and often unsuitable for analysis due to inhomogeneities, caused by changes in gauging practices over time or artificial influences. Ideally, reference (or RHN-like) catchments should be used for both short- and long-term analyses, but where this is not possible, non-reference catchments can be used for multi-temporal analysis, with appropriate caution (as in, e.g. Hannaford and Buys, 2012). Where long records of river flow are unavailable, reconstruction methods from rainfall (e.g. Wilby, 2006) or multi-model simulations (Stahl et al., 2012) may be useful. Other useful sources of data such as historical documentary information (e.g. Brázdil et al., 2006) have much potential for placing recent trends in a longterm context, even if the full multi-temporal approach advocated here is not possible - see Schmocker-Fackel and Naef (2010b) for an example application. A final cautionary note is that long records often gauge large catchments, whereas reference catchments are often small - this must also be considered in any analysis which uses different datasets to span across time and space scales (e.g. see the cautionary investigation by Viviroli et al., 2012).
Supplementary material related to this article is available online at: http://www.hydrol-earth-syst-sci.net/ 17/2717/2013/hess-17-2717-2013-supplement.pdf.

Acknowledgements. Funding was provided by the EU WATCH project (WATer and global CHange), EC Priority Area "Global Change and Ecosystems", contract number 036946. J. Hannaford and G. Buys also acknowledge additional funding from the UK Natural Environment Research Council. The study is also a contribution to UNESCO IHP-VII and the Euro-FRIEND project. The authors thank all data providers, and the national authorities for the observed streamflow records. The two anonymous reviewers are gratefully acknowledged for their suggestions for improvements to the paper.

Edited by: S. Seneviratne

\section{References}

Bard, A., Renard, B., and Lang, M.: The AdaptAlp Dataset. Description, guidance and analyses. Final Report, UR HHLY, Hydrology-Hydraulics Lyon, 15 pp., 2011.

Bard, A., Renard, B., and Lang, M.: Floods in the Alpine areas of Europe, in: Changes in flood risk in Europe, edited by: Kundzewicz, Z., International Association of Hydrological Sciences - Special Publication 10 (Blue Book series), 362-371, 2012.

Bordi, I., Fraedrich, K., and Sutera, A.: Observed drought and wetness trends in Europe: an update, Hydrol. Earth Syst. Sci., 13, 1519-1530, doi:10.5194/hess-13-1519-2009, 2009.

Bouwer, L. M., Vermaat, J. E., and Aerts, J. C. J. H.: Regional sensitivities of mean and peak river discharge to climate variability in Europe, J. Geophys. Res. 113, D19103, doi:10.1029/2008JD010301, 2008.

Brázdil, R., Kundzewicz, Z. W., and Benito G.: Historical hydrology for studying flood risk in Europe, Hydrolog. Sci. J., 51, 739764, 2006.

Burn, D. H., Sharif, M., and Zhang, K.: Detection of trends in hydrological extremes for Canadian watersheds, Hydrol. Process., 24, 1781-1790, 2010.

Burn, D. H., Hannaford, J., Hodgkins, G. A., Whitfield, P., Thorne, R., and Marsh, T. J.: Hydrologic Reference Networks II. Using Reference Hydrologic Networks to assess climate driven change, Hydrolog. Sci. J., 57, 1580-1593, 2012.

Chandler, R. and Scott, M.: Statistical methods for trend detection and analysis in the environmental sciences, Wiley, Chichester, UK, 2011.

Chen, Z. and Grasby, S. E.: Impact of decadal and century-scale oscillations on hydroclimate trend analyses, J. Hydrol., 365, 122133, 2009.

Clarke, R. T.: On the (mis)use of statistical methods in hydroclimatological research, Hydrolog. Sci. J., 55, 139-144, 2010. 
Cohn, T. A. and Lins, H. F.: Nature's style: Naturally trendy, Geophys. Res. Lett., 32, L23402, doi:10.1029/2005GL024476, 2005.

Dai, A., Qian, T., Trenberth, K. E., and Milliman, J. D.: Changes in Continental Freshwater Discharge from 1948 to 2004, J. Climate, 22, 2773-2792, 2009.

Dong, B. W., Sutton, R. T., and Woollings, T.: Changes of interannual NAO variability in response to greenhouse gases forcing, Clim. Dynam., 37, 1621-1641, 2011.

Fiala, T., Ouarda, T. B. M. J., and Hladný, J.: Evolution of low flows in the Czech Republic, J. Hydrol., 393, 206-218, 2010.

Giorgi, F., Im, E. S., Coppola, E., Diffenbaugh, N. S., Gao, X. J., Mariotti, L., and Shi, Y.: Higher Hydroclimatic Intensity with Global Warming, J. Climate, 24, 5309-5324, 2011.

Giuntoli, I., Renard, B., and Lang, M.: Floods in France, in: Changes in flood risk in Europe, edited by: Kundzewicz, Z., International Association of Hydrological Sciences - Special Publication 10 (Blue Book series), IAHS Wallingford, 199-211, 2012.

Giuntoli, I., Renard, N., Vidal, J. P., and Bard, A.: Low flows in France and their relationship to large-scale climate indices, J. Hydrol., 482, 105-118, 2013.

Gudmundsson, L., Tallaksen, L. M., Stahl, K., and Fleig, A. K.: Low-frequency variability of European runoff, Hydrol. Earth Syst. Sci., 15, 2853-2869, doi:10.5194/hess-15-28532011, 2011.

Hamed, K. H.: Exact distribution of the Mann-Kendall trend test statistic for persistent data, J. Hydrol., 365, 86-94, 2009.

Hannaford, J. and Buys, G.: Trends in seasonal river flow regimes in the UK, J. Hydrol., 475, 158-174, 2012.

Hannaford, J. and Marsh, T. J.: High-flow and flood trends in a network of undisturbed catchments in the UK, Int. J. Climatol., 28, 1325-1338, 2008.

Hannaford, J., Lloyd-Hughes, B., Keef, C., Parry, S., and Prudhomme, C.: Examining the large-scale spatial coherence of European drought using regional indicators of precipitation and streamflow deficit, Hydrol. Process., 25, 1146-1162, 2011.

Hannah, D. M., Demuth, S., van Lanen, H. A. J., Looser, U., Prudhomme, C., Rees, G., Stahl, K., and Tallaksen, L. M.: Large-scale river flow archives: importance, current status and future needs, Hydrol. Process., 25, 1191-1200, 2011.

Hodgkins, G. A.: Streamflow changes in Alaska between the cool phase (1947-1976) and the warm phase (1977-2006) of the Pacific Decadal Oscillation: The influence of glaciers, Water Resour. Res., 45, W06502, doi:10.1029/2008WR007575, 2009.

Hodgkins, G. A. and Dudley, R. W.: Changes in the timing of winter-spring streamflows in eastern North America, 1913-2002, Geophys. Res. Lett., 33, L06402, doi:10.1029/2005GL025593, 2006.

Huntington, T. G.: Evidence for intensification of the global water cycle: Review and synthesis, J. Hydrol., 319, 83-95, 2006.

IPCC: Climate Change 2007: The Physical Science Basis. Contribution of Working Group I to the Fourth Assessment Report of the Intergovernmental Panel on Climate Change, edited by: Solomon, S., Qin, D., Manning, M., Chen, Z., Marquis, M., Averyt, K. B., Tignor, M., and Miller, H. L., Cambridge University Press, Cambridge, UK and New York, NY, USA, 996 pp., 2007.

Jain, S., Hoerling, M., and Eischeid, J.: Decreasing reliability and increasing synchroneity of western North American streamflow, J. Climate, 18, 613-618, 2005.
Khaliq, M. N., Ouarda, T. B. M. J., and Gachon, P.: Identification of temporal trends in annual and seasonal low flows occurring in Canadian rivers: The effect of short- and long-term persistence, J. Hydrol., 369, 183-197, 2009.

Korhonen, J. and Kuusisto, E.: Long-term changes in the discharge regime in Finland, Hydrol. Res., 41, 253-268, 2010.

Koutsoyiannis, D.: Climate change, the Hurst phenomenon, and hydrological statistics, Hydrolog. Sci. J., 48, 3-24, 2003.

Kundzewicz, Z. W. and Robson, A. J.: Change detection in hydrological records - a review of the methodology, Hydrolog. Sci. J., 49, 7-19, 2004.

Lavers, D. A., Villarini, G., Allan, R. P., Wood, E. F., and Wade, A. J.: The detection of atmospheric rivers in atmospheric reanalyses and their links to British winter floods and the large-scale climatic circulation, J. Geophys. Res.-Atmos., 117, D20106, doi:10.1029/2012JD018027, 2012.

López-Moreno, J. I. and Vicente-Serrano, S. M.: Positive and Negative Phases of the Wintertime North Atlantic Oscillation and Drought Occurrence over Europe: A Multitemporal-Scale Approach, J. Climate, 21, 1220-1243, 2008.

Lorenzo-Lacruz, J., Vicente-Serrano, S. M., López-Moreno, J. I., González-Hidalgo, J. C., and Morán-Tejeda, E.: The response of Iberian rivers to the North Atlantic Oscillation, Hydrol. Earth Syst. Sci., 15, 2581-2597, doi:10.5194/hess-15-25812011, 2011.

Lorenzo-Lacruz, J., Vicente-Serrano, S. M., Lopez-Moreno, J. I., Moran-Tejeda, E., and Zabalza, J.: Recent trends in Iberian streamflows (1945-2005), J. Hydrol., 414, 463-475, 2012.

Luce, C. H. and Holden, Z. A.: Declining annual streamflow distributions in the Pacific Northwest United States, 1948-2006, Geophys. Res. Lett., 36, L16401, doi:10.1029/2009GL039407, 2009.

Majercakova, O., Fendekova, M., and Leskova, D.: The variability of hydrological series due to extreme climatic conditions and the possible change of the hydrological characteristics with respect to potential climate change, in: FRIEND'97 - Regional Hydrology: concepts and Models for Sustainable Water Management, IAHS Publication, 246, 59-65, 1997.

Marsh, T. and Harvey, C. L.: The Thames flood series: a lack of trend in flood magnitude and a decline in maximum levels, Hydrol. Res., 43, 203-214, 2012.

McCabe, G. J. and Wolock, D. M.: A step increase in streamflow in the conterminous United States, Geophys. Res. Lett., 29, 2185, doi:10.1029/2002GL015999, 2002.

Milly, P. C., Dunne, K. A., and Vecchia, A. V.: Global pattern of trends in streamflow and water availability in a changing climate, Nature, 438, 347-350, 2005.

Murphy, C., Harrigan, S., Hall, J., and Wilby, R. L.: Climate-driven trends in mean- and high- flows from a network of reference stations in Ireland, Hydrolog. Sci. J., 58, 755-772, 2013.

Pagano, T. and Garen, D.: A recent increase in western US streamflow variability and persistence, J. Hydrometeorol., 6, 173-179, 2005.

Parry, S., Hannaford, J., Prudhomme, C., Lloyd-Hughes, B., and Williamson, J.: Objective drought and high flow catalogues for Europe, WATCH Technical Report 33, Water and Global Change Project, Wallingford, 57 pp., available at: http://www.eu-watch. org/publications/technical-reports, 2011.

Pekarova, P., Miklanek, P., and Pekar, J.: Spatial and temporal runoff oscillation analysis of the main rivers of the world during 
the 19th-20th centuries, J. Hydrol., 274, 62-79, 2003.

Petrow, T., Zimmer, J., and Merz, B.: Trends in flood magnitude, frequency and seasonality in Germany in the period 1951-2002, J. Hydrol., 371, 129-141, 2009.

Probst, J. L. and Tardy, Y.: Long-Range Streamflow and World Continental Runoff Fluctuations since the Beginning of This Century, J. Hydrol., 94, 289-311, 1987.

Radziejewski, M. and Kundzewicz, Z. W.: Detectability of changes in hydrological records, Hydrolog. Sci. J., 49, 39-51, 2004.

Renard, B., Lang, M., Bois, P., Dupeyrat, A., Mestre, O., Niel, H., Sauquet, E., Prudhomme, C., Parey, S., Paquet, E., Neppel, L., and Gailhard, J.: Regional methods for trend detection: assessing field significance and regional consistency, Water Resour. Res., 44, W08419, doi:10.1029/2007WR006268, 2008.

Rennermalm, A. K., Wood, E. F., and Troy, T. J.: Observed changes in pan-arctic cold-season minimum monthly river discharge, Clim. Dynam., 35, 923-939, 2010.

Schmocker-Fackel, P. and Naef, F.: More frequent flooding? Changes in flood frequency in Switzerland since 1850, J. Hydrol., 381, 1-8, 2010a.

Schmocker-Fackel, P. and Naef, F.: Changes in flood frequencies in Switzerland since 1500, Hydrol. Earth Syst. Sci., 14, 1581-1594, doi:10.5194/hess-14-1581-2010, 2010b.

Shiklomanov, A. I. and Lammers, R. B.: Record Russian river discharge in 2007 and the limits of analysis, Environ. Res. Lett., 4, 045015, doi:10.1088/1748-9326/4/4/045015, 2009.

Sousa, P. M., Trigo, R. M., Aizpurua, P., Nieto, R., Gimeno, L., and Garcia-Herrera, R.: Trends and extremes of drought indices throughout the 20th century in the Mediterranean, Nat. Hazards Earth Syst. Sci., 11, 33-51, doi:10.5194/nhess-11-33-2011, 2011.

Stahl, K., Hisdal, H., Hannaford, J., Tallaksen, L. M., van Lanen, H. A. J., Sauquet, E., Demuth, S., Fendekova, M., and Jódar, J.: Streamflow trends in Europe: evidence from a dataset of nearnatural catchments, Hydrol. Earth Syst. Sci., 14, 2367-2382, doi:10.5194/hess-14-2367-2010, 2010.

Stahl, K., Tallaksen, L. M., Hannaford, J., and van Lanen, H. A. J.: Filling the white space on maps of European runoff trends: estimates from a multi-model ensemble, Hydrol. Earth Syst. Sci., 16, 2035-2047, doi:10.5194/hess-16-2035-2012, 2012.

Svensson, C., Hannaford, J., Kundzewicz, Z. W., and Marsh, T.: Trends in river floods: why is there no clear signal in observations?, in: Frontiers in Flood Research, Proceedings of Kovacs Colloquium, Paris, June 2006, IAHS Publ. 305, 2006.

Svensson, C., Kundzewicz, Z. W., and Maurer, T.: Trend detection in river flow series: 2 . Flood and low-flow index series, Hydrolog. Sci. J., 50, 811-824, 2005.
Sutton, R. and Dong, B.: Atlantic Ocean influence on a shift in European climate in the 1990s, Nat. Geosci., 5, 788-792, 2012.

Trnka, M., Dubrovsky, M., Svoboda, M., Semeradova, D., Hayes, M., Zalud, Z. and Wilhite, D.: Developing a regional drought climatology for the Czech Republic, Int. J. Climatol., 29, 863883, 2009.

Ummenhofer, C. C., England, M. H., McIntosh, P. C., Meyers, G. A., Pook, M. J., Risbey, J. S., Gupta, A. S., and Taschetto, A. S.: What causes southeast Australia's worst droughts?, Geophys. Res. Lett., 36, L04706, doi:10.1029/2008GL036801, 2009.

van der Schrier, G., Efthymiadis, D., Briffa, K. R., and Jones, P. D.: European Alpine moisture variability for 1800-2003, Int. J. Climatol., 27, 415-427, 2007.

Verpe-Dyrdall, A., Saloranta, T., Skaugen, T., and Bache-Stranden, H.: Changes in snow depth in Norway during the period 19612010, Hydrol. Res., 44, 169-179, 2013.

Villarini, G., Smith, J. A., Serinaldi, F., and Ntelekos, A. A.: Analyses of seasonal and annual maximum daily discharge records for central Europe, J. Hydrol., 399, 299-312, 2011.

Viviroli, D., Schadler, B., Schmocker-Fackel, P., Weiler, M., and Seibert, J.: On the risk of obtaining misleading results by pooling streamflow data for trend analyses, Water Resour. Res., 48, W05601, doi:10.1029/2011WR011690, 2012.

Whitfield, P., Burn, D., Hannaford, J., Higgins, H., Hodgkins, G. A., Marsh, T. J., and Looser, U.: Hydrologic Reference Networks I. The Status of National Reference Hydrologic Networks for Detecting Trends and Future Directions, Hydrolog. Sci. J., 57, 1562-1579, 2012.

Wilby, R. L.: When and where might climate change be detectable in UK river flows?, Geophys. Res. Lett., 33, L19407, doi:10.1029/2006GL027552, 2006.

Wilson, D., Hisdal, H., and Lawrence, D.: Has streamflow changed in the Nordic countries? - Recent trends and comparisons to hydrological projections, J. Hydrol., 394, 334-346, 2010.

Woo, M.-K., Thorne, R., and Szeto, K. K.: Reinterpretation of streamflow trends based on shifts in large-scale atmospheric circulation, Hydrol. Process., 20, 3995-4003, 2006.

Wrzesiński, D. and Paluszkiewicz, R.: Spatial differences in the impact of the North Atlantic Oscillation on the flow of rivers in Europe, Hydrol. Res., 42, 30-39, 2010.

Zaidman, M. D., Rees, H. G., and Young, A. R.: Spatio-temporal development of streamflow droughts in north-west Europe, Hydrol. Earth Syst. Sci., 6, 733-751, doi:10.5194/hess-6-733-2002, 2002. 